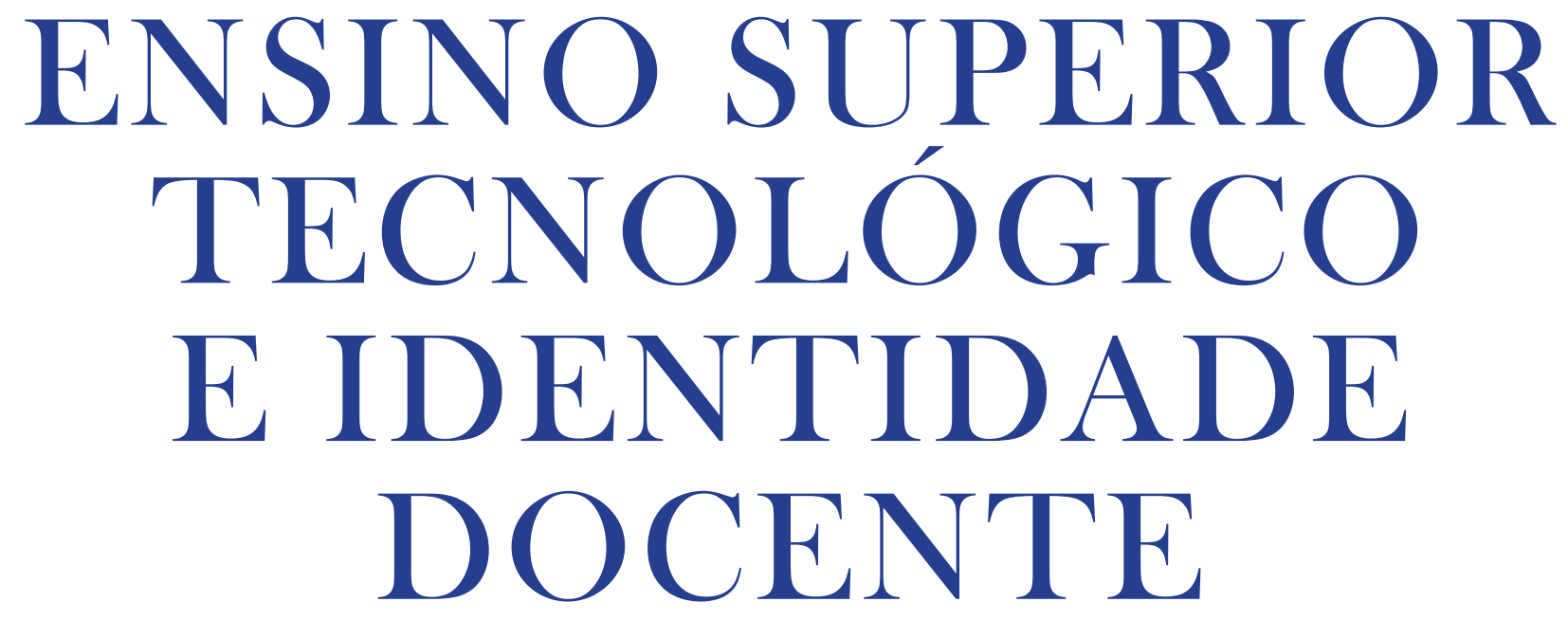

TECHNOLOGICAL HIGHER EDUCATION AND TEACHING IDENTITY ENSEÑANZA SUPERIOR TECNOLÓGICA E IDENTIDAD DOCENTE

Paulo Fossatti Doutor em Educação pela PUC/RS. Docente do Mestrado em Educação da UNILASALLE.

\title{
Suzana Trevisan
}

Mestra em Educação pela UNILASALLE.

Mestrado em Educação Centro Universitário La Salle (UNILASALLE) Canoas - RS - Brasil

Endereço:

Av. Victor Barreto, 2288, Centro - Canoas - RS CEP: $92110-000$

E-mails:

irpaulo@unilasalle.edu.br suzanatrevisan@sapucaia.ifsul.edu.br 
Resumo: O presente artigo tem por objetivo revisar a literatura voltada para a construção da identidade docente dos professores brasileiros do Ensino Superior Tecnológico que não possuem formação específica voltada para a docência. Além da legislação brasileira, a pesquisa centra-se nos pressupostos do Construtivismo Piagetiano, pela reflexão de Paulo Freire na construção crítica do conhecimento e pela problematização dos saberes docentes à luz de Tardif. Os achados da pesquisa sinalizam para a construção de uma identidade docente pautada na construção do conhecimento; na formação inicial e continuada do professor; na vivência dos saberes docentes defendidos por Tardif; no resgate histórico da Educação Profissional e das diretrizes para a Educação Superior Tecnológica brasileira.

Palavras-chave: Identidade docente. Saberes Docentes. Ensino Superior Tecnológico.

Abstract: This article aims to review the literature focused on the construction of identity of Brazilian teachers in technological higher education who do not have specific training for this teaching. In addition to the Brazilian legislation, the research focuses on the assumptions of the Piagetian Constructivism, by the reflection of Paulo Freire in the critical construction of knowledge and the questioning of teaching knowledge in the light of Tardif. The findings of the research indicate the construction of a teacher's identity that is based on the construction of knowledge; on the initial and continuing education of the teacher; in the experience of the teaching knowledge defended by Tardif; in the historic rescue of Professional Education and the guidelines for Brazilian Technological Higher Education. 
Keywords: Teacher identity. Teaching knowledge.

Technological Higher Education.

Resumen: El presente artículo tiene por objetivo revisar la literatura dirigida hacia la construcción de la identidad docente de los profesores brasileños de la Enseñanza Superior Tecnológica que no tienen formación específica en la docencia. Además de la legislación brasileña, la investigación se centra en los presupuestos del Constructivismo Piagetiano a través de la reflexión de Paulo Freire en la construcción crítica del conocimiento y de la problematización de los saberes docentes desde el punto de vista de Tardif. Los hallazgos de la investigación indican la construcción de una identidad docente pautada en la construcción del conocimiento, en la formación inicial y continua del profesor, en la vivencia de los saberes docentes defendidos por Tardif, en el rescate histórico de la Educación Profesional y de las directrices para la Educación Superior Tecnológica brasileña.

Palabras clave: Identidad docente. Saberes Docentes. Enseñanza Superior Tecnológica.

INTRODUÇÃO

V ive-se em um tempo, de tal maneira particular na história, que quando se pensa na situação da ciência, tem-se a impressão de que, devido ao imenso salto científico dado ao longo do século XX e no início desse século, aqueles anos que os precederam parecem obsoletos. Entretanto, este desenvolver frenético da ciência e da tecnologia nem sempre deixa o espaço para a reflexão: até que ponto se utilizam essas descobertas para se pensar a docência nesta sociedade tão plural em que se vive?

As instituições de ensino têm enfrentado o desafio de adequar suas práticas frente às novas necessidades sociais, culturais, tecnológicas e individuais também como parte desse todo social. 
O governo brasileiro também se mostra atento e algumas medidas, como a criação de políticas públicas de amparo social aos menos favorecidos e a consolidação da economia, produziram reflexos no cenário educacional. Sem dúvida, a criação dos cursos superiores tecnológicos, no Brasil, ilustra essa iniciativa, já que, conforme os decretos n. 2.208 (de 17 de abril de 1997) e n. 5.154 (de 23 de julho de 2004), esse nível tem objetivo de formar profissionais para atender campos delimitados do mercado de trabalho.

A criação desses cursos também trouxe uma mudança significativa para o paradigma de formação discente: se o fator econômico (e, portanto, a preparação da mão de obra) era o aspecto mais importante do ensino técnico no século passado, o foco do Ensino Superior Tecnológico passa ser a possibilidade de inclusão social. Esta se dá basicamente por meio de um ensino voltado para a formação de profissionais aptos a desenvolver atividades de uma determinada área de maneira plena e inovadora.

Portanto, as instituições de ensino brasileiras têm enfrentado o desafio de se adequar. $O$ governo também tem realizado esforços no sentido de ampliar o acesso ao ensino profissionalizante. Contudo, como os professores têm construído sua identidade profissional em meio a tantas mudanças? E quanto à identidade daqueles profissionais formados em outras áreas que passam a exercer a docência sem nenhuma formação pedagógica específica?

Por acreditar que a atuação docente seja parte fundamental do processo educativo, muitos pesquisadores têm se preocupado com o sujeito "professor", sua formação e os reflexos em sua prática. Particularmente neste artigo, a investigação recai sobre o processo de construção da identidade docente daqueles que atuam no Ensino Superior Tecnológico e que não possuem prévia formação pedagógica. O método faz uso da revisão de literatura e legislação brasileira sobre a temática em discussão.

\section{REVISÃO DE LITERATURA: ACHADOS DA PESQUISA}

\section{A CONSTRUÇÃO DO CONHECIMENTO}

Ao se iniciar a problematização sobre a construção da identidade docente, questiona-se sobre a identidade docente daqueles que não tiveram formação 
específica para atuar nessa área. Mesmo que não tivessem frequentado um curso de formação inicial para o magistério, possuíam diretrizes sobre o processo de ensino e aprendizagem? Como eles haviam construído seus referenciais didáticopedagógicos?

Na tentativa de compreender o processo de construção do conhecimento, buscou-se revisitar a literatura dos últimos anos, pois ao longo do tempo, diferentes paradigmas tentaram explicar o processo de ensino e aprendizagem na educação formal. Dentre esses, faz-se o recorte do olhar construtivista, porque se considera que a opção teórica se aproxima desta proposta.

Ao se iniciar com Piaget (FRANCO, 1995), destaca-se que ele deparouse com duas grandes correntes que desejavam compreender a produção de conhecimento (o empirismo e o apriorismo) e julgou que nenhuma delas era capaz de explicar plenamente esse processo. A Psicologia Behaviorista acreditava que o conhecimento estava na natureza e o homem apenas o captava. $O$ modelo empirista de Skinner e Watson, no entanto, acredita que "na relação sujeito-objeto (condição necessária para que haja conhecimento) é o objeto que imprime o conhecimento no sujeito através de um esquema estímulo-resposta ou mesmo resposta-reforço" (FRANCO, 1995, p. 18 e 19). A aprendizagem, portanto, denomina-se como uma mudança de comportamento que aquele que ensina (ou impõe) gera naquele que aprende.

Nesse paradigma, poder-se-ia inferir que a identidade docente seria essencialmente construída ao longo da formação inicial, sendo que os futuros professores "absorveriam" os saberes de seus professores e permaneceriam passivos em relação à aprendizagem?

No olhar da Psicologia da Gestalt (BECKER, 2009), a explicação para tal processo dá-se por meio do modelo apriorista, acreditando que o conhecimento fosse fruto de uma capacidade interna inata. A pedagogia seria, então, centrada no aluno e o professor se preocuparia apenas em provocar o interesse deles, por meio de uma prática voltada para técnicas de motivação. Nesse paradigma, a identidade docente seria intimamente relacionada com um saber vocacionado, interno e que, por isso, algumas pessoas nasceriam com o "dom" ou a "propensão" para serem professores?

Piaget concordou com o behaviorismo, na medida em que afirma que o conhecimento vem da experiência, mas admitiu que só ela não é capaz de explicar 
a construção do conhecimento (BECKER, 2009). Da mesma forma, concordou com a Gestalt, porque ela demonstra a necessidade de processos internos para que o conhecimento seja possível, mas apontou que eles não são inatos, já que as experiências podem modificá-los.

Piaget (FRANCO, 1995) não estava interessado em propor nenhuma teoria sobre aprendizagem, mas como estudava o processo do conhecimento e a construção do raciocínio, sua teoria acabou trazendo inovações para a psicologia e para a pedagogia.

O construtivismo trouxe consigo uma nova concepção de inteligência: a inteligência de forma qualitativa. Seus achados permitiram a compreensão de que a aprendizagem não se dá quando o professor professa suas ideias e os alunos as anotam ou as decoram. Ao mesmo tempo, também não é a situação em que o aluno faz o que quer e o professor fica passivo, apenas observando.

Dessa forma, questiona-se como os professores que não tiveram uma formação inicial para a docência constroem sua identidade docente? Seria por meio do exercício profissional? Haverá um saber vocacionado, apriorista? Os saberes docentes edificam-se no depósito de filosofia e teorias educacionais? Os professores possuem os mesmos saberes no início e no final de suas carreiras? Procura-se, na próxima seção, analisar o que alguns autores afirmam sobre estas interrogações sobre a formação docente, bem como compreender as mudanças que ela sofreu nos últimos anos.

\section{O PROFESSOR E A SUA FORMAÇÃO}

É consenso entre os pesquisadores a relevância da formação inicial para o processo de construção da identidade docente. Imbernón (2010) pontua que a preocupação com a formação dos professores é bastante antiga: ela foi exercida "desde a Antiguidade, desde o momento em que alguém decidiu que os outros educariam os seus filhos e esses outros tiveram que se preocupar em fazê-lo".

Mizukami (2002) entende que o papel desta formação é essencialmente fornecer bases que contribuam para a construção de um conhecimento pedagógico especializado. Porém, embora necessária, a formação inicial não se mostra suficiente se se encarar a formação dos professores para além da aquisição de conhecimentos técnicos. 
A discussão sobre o paradigma eleito na formação dos alunos do ensino básico também cabe para a formação inicial docente: seguem-se os moldes bancários, "a memorização mecânica do conteúdo narrado" perpetua a visão distorcida da educação, porque "não há criatividade, não há transformação, não há saber" (FREIRE, 2005, p. 66).

Freire também constata que "Só existe saber na invenção, na reinvenção, na busca inquieta, impaciente, permanente, que os homens fazem no mundo, com o mundo e com os outros" (FREIRE, 2005, p. 67).

O fato de que muitos de nós, atuais professores, recebam como alunos a educação "bancária", pode ser apontado como um pequeno entrave nessa mudança. "Ora, minha prática é assim porque aprendi assim", diriam alguns. Entretanto, hoje, mais do que nunca, há a necessidade de uma reforma educacional: a contemporaneidade requer que os aprendizes se preocupem não apenas em adquirir informações, mas saber o que fazer com elas. Além disso, há de se articular, professores, alunos e todos os demais sujeitos envolvidos nesse processo a fim de compartilhar ideias coletivas: o aprender será, então, fruto de uma construção, porque a educação "bancária" (FREIRE, 2005) impõe a passividade e a ingenuidade e serve como instrumento de opressão.

Além disso, a profissão docente exige preparo e reflexão contínua sobre o seu fazer, sendo mais do que um fazer vocacionado. Por isso, a formação continuada tem papel decisivo na construção de um profissional reflexivo. Imberón (2010, p. 13) garante que essa formação é um processo mais recente historicamente, que contempla:

[...] a inquietação de saber como [...], de que maneira, com quais conhecimentos, com quais modelos, quais modalidades de formação são mais inovadoras e, sobretudo, a inquietação de ter a consciência de que a teoria e a prática da formação devem ser revisadas e atualizadas [...].

Esse mesmo autor afirma que as décadas de 70, 80 e 90 foram decisivas para o avanço dessa área. Entretanto, os últimos 10 anos é que demarcam uma época de grandes mudanças. Para ele, além da reflexão sobre a prática, faz-se necessário "uma indagação constante sobre a formação do professor, seja inicial ou continuada" (IMBERÓN, 2010, p. 14).

Os anos 70 foi um período marcado pela ideia de que a formação continuada era um processo individual: "[...] cada um buscava para si a vida formativa, ou seja, primava-se pela formação inicial, que era melhor ou pior segundo a época 
e o território, e se aplicava à formação continuada a idéia forme-se onde puder e como puder" (IMBERNÓN, 2010, p. 16).

A década seguinte foi de transição: as ideias pós-modernas estavam se introduzindo na sociedade. Entretanto, o paradigma da racionalidade técnica trazia ainda a busca das competências de um bom professor. Nesse modelo, "a teoria é compreendida como um conjunto de princípios gerais e conhecimentos científicos, e a prática como a aplicação da teoria e da técnica científica" (ALMEIDA; BIAJONE, 2007, p. 291). Assim, as técnicas de ensino eram apresentadas aos futuros professores como saberes científicos, portanto inquestionáveis e universais, e eles, por sua vez, realizavam a aplicação dessas técnicas ou teorias. Por isso, as universidades organizavam cursos de treinamento, ignorando a reflexão e a análise como meios fundamentais para a formação docente.

Somente nos anos 90 algumas mudanças começaram a surgir. Com a institucionalização da formação surge também a preocupação do âmbito universitário com estudos teóricos. É nesse período que as ideias de Schön são difundidas em grande parte da Espanha, assim como alguns países latinoamericanos, desenvolve novas modalidades como a formação em escolas ou em seminários permanentes.

Donald Schön cria um novo modelo de formação ao reconhecer que o paradigma anterior apresentava limitações, já que o docente, responsável pela execução de "receitas prontas", não refletia sobre a sua ação profissional. Ele então "propõe a superação da formação nos moldes de um currículo normativo e de caráter técnico-profissional" (ALMEIDA; BIAJONE, 2007, p. 291).

O novo modelo da racionalidade prática reconhece os professores como produtores de saberes e valoriza a sua subjetividade, tentando legitimar um repertório de conhecimentos sobre o ensino, partindo do que os professores são, fazem e sabem.

\section{OS SABERES DOCENTES}

Gauthier, Tardif e Shulman, investigadores dos saberes docentes, acreditam na ideia de que os professores têm uma base de conhecimento (knowledge base). Essa concepção foi fundamental para os movimentos de reforma na formação inicial dos professores da educação básica que ocorreu nos Estados Unidos e no 
Canadá no final dos anos 80. Dentre outros objetivos, essa reforma buscava a afirmação de um status profissional para os profissionais da educação, superando a ideia do fazer docente como um fazer vocacionado.

Almeida e Biajone (2007) destacam que acreditar no modelo de racionalidade prática sugere, necessariamente, a valorização do conhecimento dos professorese o reconhecimento de tais como colaboradores e parceiros nas práticas formativas. Esses autores trazem algumas pesquisas acerca da formação de professores, citando as contribuições dos três autores citados anteriormente que criaram diferentes concepções e tipologias sobre os saberes docentes.

Gauthier afirma que o desafio da profissionalização docente é exercer o ofício feito de saberes. Para ele, o ensino se dá "como a mobilização de vários saberes que formam uma espécie de reservatório que é utilizado para responder às exigências das situações concretas de ensino" (ALMEIDA; BIAJONE, 2007, p. 285). Ele vê o professor como sujeito capaz de deliberar, julgar e decidir sobre a ação a ser tomada, pois é munido de saberes e confronta-os com a situação que se coloca.

A teoria de Shulman, por sua vez, afirma que:

[...] o aprendizado a partir da prática é a melhor descrição do que se poderia denominar de aprendizado para ensinar, pois é por meio dele que se tem a oportunidade de aprender a lidar com a surpresa, a incerteza e a complexidade intrínseca ao microcosmo do cotidiano da sala de aula. (ALMEIDA; BIAJONE, 2007, p. 292).

Maurice Tardif (2012), por sua vez, questiona quais devem ser os saberes necessários para a atuação profissional dos professores. Ele acredita que seus saberes são parte de um processo em permanente construção ao longo da carreira profissional.

No que diz respeito à legislação, especialmente no cenário do Ensino Superior Tecnológico, o professor deverá ter a mesma formação exigida para a docência no Ensino Superior: "[...] a preparação para o exercício do magistério superior farse-á em nível de pós-graduação, prioritariamente em programas de mestrado e doutorado" (BRASIL, 2002, p. 52).

O parecer citado chama a atenção para o fato de que tanto a competência como a experiência na área deverão ser consideradas, bem como o requisito acadêmico, devido às características dessa modalidade de ensino. Assim, os saberes provenientes da experiência profissional, adquiridos no exercício da profissão extradocente, são julgados valiosos e devem interferir na atuação do professor. Mas não podem ser os únicos. 
Tardif (2012) define o saber dos professores como um saber social, porque é compartilhado por um grupo de agentes, porque seus objetos são objetos sociais na medida em que ele atua com sujeitos e em função de um projeto de transformar, educar e instruir seus alunos e, finalmente, porque "o que" e "de que maneira ensinar" mudam ao longo do tempo e conforme as mudanças sociais. Ele ainda aponta para o fato de que os saberes dos professores dependem das condições nas quais o trabalho deles se realiza, assim como dependem da personalidade e da experiência profissional de cada indivíduo.

Esse mesmo autor denomina como heterogêneo e plural o saber profissional docente na medida em que envolve conhecimentos e um saber-fazer bastante diversos: "[...] o saber profissional está, de certo modo, na confluência de vários saberes oriundos da sociedade, da instituição escolar, dos outros atores educacionais, das universidades, etc." (TARDIF, 2012, p. 19). Esse saber docente é composto por vários outros saberes provenientes de diferentes fontes: da formação profissional, de saberes disciplinares, curriculares e experienciais.

Os saberes da formação profissional são transmitidos pelas instituições de formação de professores:

[...] esses conhecimentos se transformam em saberes destinados à formação científica ou erudita dos professores, e, caso sejam incorporados à prática docente, esta pode transformarse em prática científica, em tecnologia da aprendizagem, por exemplo. No plano institucional, a articulação entre essas ciências e a prática docente se estabelece, concretamente, através da formação inicial ou contínua dos professores. (TARDIF, 2012, p. 37).

Relacionados ainda aos saberes da formação profissional, há aqueles provenientes de reflexões sobre a prática educativa, apresentando-se como doutrinas. Esses são chamados saberes pedagógicos. Eles "articulam-se com as ciências da educação [...], na medida em que eles tentam [...] integrar os resultados da pesquisa às concepções que propõem, a fim de legitimá-las" (TARDIF, 2012, p. 37).

Os saberes disciplinares são aqueles que correspondem aos diversos campos do conhecimento. Eles são transmitidos nos cursos universitários, independentemente se ele for relacionado à área da educação ou à área técnica. Estes saberes "emergem da tradição cultural e dos grupos sociais produtores de saberes" (TARDIF, 2012, p. 38).

Já aqueles que correspondem a objetivos, métodos, conteúdos e discursos da instituição escolar, apresentando-se concretamente sob a forma de programas escolares (objetivos, conteúdos e métodos) e que os professores devem aprender e aplicar, são chamados saberes curriculares. 
Mas, sem dúvida, são os saberes experienciais que surgem como "núcleo vital do saber docente, núcleo a partir do qual os professores tentam transformar suas relações de exterioridade com os saberes em relação de interioridade com a sua própria prática" (TARDIF, 2012, p. 54). Bem como diz o nome, os saberes experienciais são aqueles que se originam na prática cotidiana da profissão e são validados por ela. É no exercício da profissão que o professor se depara com situações concretas que não se mostram passíveis de definições acabadas e que exigem dele habilidade pessoal e improvisação. Para Tardif 2012), esses saberes provindos da experiência estão em constante confronto com as condições da profissão.

Ele acrescenta ainda que a prática pode ser vista como uma oportunidade de reflexão crítica que faz com que o professor retraduza a sua formação:

A experiência provoca, assim, um efeito de retomada crítica (retroalimentação) dos saberes adquiridos antes ou fora da prática profissional. Ela filtra e seleciona os outros saberes, permitindo assim aos professores reverem seus saberes, julgá-los e avaliá-los e, portanto, objetivar um saber formado de todos os saberes retraduzidos e submetidos ao processo de validação constituído pela prática cotidiana. (TARDIF, 2012, p. 53).

\section{TRAÇOS HISTÓRICOS DA EDUCAÇÃO PROFISSIONAL NO BRASIL}

Mesmo que distante dos modelos hoje consagrados de educação técnica ou tecnológica, a capacitação de escravos e índios para o trabalho rural já se caracterizava como uma educação para a formação do trabalhador (BRASIL, 2009). Desde aquela época, essa forma de ensino ou capacitação dos trabalhadores era destinada a pessoas das classes sociais mais baixas.

A necessidade de formar mão de obra especializada para trabalhar nas casas de fundição e de moedas fez com que o governo criasse "Centros de Aprendizagem de Ofícios" no período de exploração do ouro em Minas Gerais (final do século XVII). Um século mais tarde, especificamente no ano de 1785, a Metrópole proíbe a existência de fábricas em nosso país, porque receava que a Colônia pudesse tornar-se forte e independente ${ }^{1}$.

Nosso país adotou o modelo de ensino e aprendizagem de ofícios como tipografia, alfaiataria, tornearia, carpintaria e sapataria, dentre outros, ao longo do século XIX, com o objetivo de amparar as crianças e os jovens das classes mais baixas.

O período que seguiu a abolição da escravatura foi marcado pela consolidação do ensino técnico-industrial brasileiro, fortemente influenciado pela expansão 
e fortificação da economia agrário-exportadora. Portanto, o século XX marca a consolidação do ensino voltado para o mercado de trabalho. Em 1906 foi entregue ao Congresso Nacional um projeto de promoção do ensino prático industrial, agrícola e comercial. Essa iniciativa previa a criação de campos e oficinas escolares. Os alunos do ginásio aprenderiam, então, o manuseio de instrumentos de trabalho.

Três anos mais tarde, o presidente Nilo Peçanha assinou o Decreto $n^{\circ} 7.566$ que criou 19 Escolas de Aprendizes Artífices, responsável pela oferta de ensino profissional gratuito. $O$ atributo dessas escolas como instrumento do governo no exercício de uma política moral assistencialista fica claro se se analisar a origem dessas instituições (BRASIL, 2010, p. 10):

A justificativa do Estado brasileiro, em 23 de setembro de 1909, para a criação de um conjunto de Escolas de Aprendizes Artífices era a necessidade de prover as classes proletárias de meios que garantissem a sua sobrevivência, isto é, prover os "desfavorecidos da fortuna", expressão contida no Decreto $n^{\circ} 7.566$, assinado pelo então Presidente Nilo Peçanha no ato de criação dessas escolas, uma em cada capital federativa, com duas exceções apenas. Nesse sentido, não há dúvida de que aos objetivos das Escolas de Aprendizes Artífices associavam-se a qualificação de mão de obra e o controle social de um segmento em especial: os filhos das classes proletárias, jovens e em situação de risco social, pessoas potencialmente mais sensíveis à aquisição de vícios e hábitos "nocivos" à sociedade e à construção da nação.

Considerando-se os limites da economia e da sociedade daquela época, "a educação profissional e tecnológica, por meio dessas escolas, desempenha papel relevante no enfrentamento dos desafios surgidos ao longo do processo de desenvolvimento econômico". Foi nas décadas de 30 e 40 que o Brasil sofreu uma mudança econômica que afetou diretamente o desenvolvimento desse tipo de educação: a economia desloca seu eixo de atuação para a área industrial e a existência dessas escolas profissionalizantes vai ao encontro dos interesses econômicos (BRASIL, 2010, p. 10):

Em decorrência do processo de mudança da sociedade, essas escolas vão se posicionando, de forma mais direta, vinculadas às políticas de desenvolvimento econômico, aspecto esse que consagrou sua mais visível referência: qualificar mão de obra tendo em vista o seu papel estratégico para o país, característica típica de governos no estado capitalista moderno no que concerne a sua relação com o mercado, objetivo que se complementa com a manutenção, sob controle social, dos excluídos dos processos de produção.

Simões e Castanho (2010, p. 5) apontam que a nova burguesia formada após o final da Primeira Grande Guerra exige acesso à educação. Os novos ricos desprezam a formação tecnicista e desejam uma educação acadêmica e elitista. 
Por outro lado, "o operariado exige um mínimo de escolarização, e começam as pressões para a expansão da oferta de ensino."

Somente após o ano de 1942 é que a formação profissional passa a ser um nível equivalente ao secundário. Nas duas décadas seguintes surge a expansão da indústria automobilística, assim como os investimentos nos setores de energia e transporte. No final da década de 50, as escolas industriais e técnicas ganham autonomia didática e de gestão e são nomeadas escolas técnicas federais. A intensificação da formação de profissionais ocorre nesses anos, já que o processo de industrialização está "a todo vapor" no Brasil.

A década de 70 foi um período de fortes mudanças nas políticas da educação profissional:

Em 1971, a Lei de Diretrizes e Bases da Educação Brasileira (LDB) transforma, de maneira compulsória, todo currículo do segundo grau em técnico-profissional, reflexo desse momento histórico. Um novo paradigma estabelece-se: formar técnicos sob o regime da urgência. Nesse tempo, as Escolas Técnicas Federais aumentam expressivamente o número de matrículas e implantam novos cursos técnicos. (BRASIL, 2010, p. 11).

Simões e Castanho (2010, p. 8) ressaltam que o grande objetivo do governo, naquela época, era "colocar o Brasil no sistema do capitalismo internacional, tratando a educação como capital humano". Dessa forma, a educação atenderia às exigências sociais de economia de tempo, de esforços e de custos. "Desta forma, a educação tecnicista se encontra imbuída dos ideais de racionalidade, organização, objetividade e eficiência. Tudo para alcançar mais eficiência e produtividade."

Sofre-se, entretanto, uma retração do desenvolvimento, um desequilíbrio da economia nos anos 80 e o início da década de 90. Os organismos financeiros internacionais criam uma série de exigências e a maior parte das medidas tomadas pelo governo está ligada ao controle da inflação.

É somente na segunda metade da década de 90 que começa o processo de mudança do modelo educacional profissionalizante. O debate realizado em algumas escolas federais tinha por objetivo promover uma reforma não só curricular, mas também que apontasse para uma nova pedagogia institucional. "O principal objetivo era alinhar as políticas e ações das instituições ao cenário, com destaque para aquele que demarcava as demandas sociais locais e regionais" (BRASIL, 2010, p. 12).

Por isso, mesmo que em 1969 o Decreto-Lei 547/69 já autorizasse a organização e o funcionamento de cursos profissionais superiores de curta duração, é somente 
em outubro de 2000 que a proposta de Diretrizes Curriculares Nacionais para a Educação Profissional de Nível Tecnológico é encaminhada à deliberação do Conselho Nacional de Educação.

\section{UM NOVO MODELO DE ENSINO SUPERIOR TECNOLÓGICO BRASILEIRO}

Mudanças ao modelo anterior de Ensino Profissionalizante foram propostas nas Diretrizes Curriculares Nacionais para a Educação Profissional de Nível Tecnológico a fim de tornar o ensino coerente com as necessidades de nosso tempo. Conforme o Parecer CNE/CP n² 29/2002:

A proposta do MEC apresenta os cursos superiores de tecnologia como "uma das principais respostas do setor educacional às necessidades e demandas da sociedade brasileira", uma vez que o progresso tecnológico vem causando profundas "alterações nos modos de produção, na distribuição da força de trabalho e na sua qualificação" (BRASIL, 2002, p. 2).

O Parecer CNE/CES n436/01, homologado pelo Ministério da Educação em abril de 2001, destaca que o Curso Superior de Tecnologia deve formar um profissional apto a desenvolver atividades de uma determinada área profissional de maneira plena e inovadora. Além disso, afirma que a permanente ligação destes cursos com o meio produtivo faz com que eles sofram contínua atualização, renovação e autoestruturação.

O Parecer CNE/CP n²9/2002 chama a atenção para a importância de delimitar e esclarecer critérios e referenciais suficientemente claros e de responsabilidade das instituições de ensino.

Inicialmente, os profissionais tecnólogos estavam ligados aos campos da engenharia, eletrotécnica e informática. Entretanto, os "setores de comércio e serviços constituem mesmo um notável universo em expansão" (BRASIL, 2002, p. 29).

O Catálogo Nacional de Cursos Superiores de Tecnologia aponta treze eixos tecnológicos (ambiente e saúde; apoio escolar; controle e processos industriais; gestão e negócios; hospitalidade e lazer; informação e comunicação; infraestrutura; militar; produção alimentícia; produção cultural e design; produção industrial; recursos naturais e segurança) e adverte:

A listagem de cursos constante deste catálogo, contudo, não esgota todas as possibilidades de oferta destas graduações tecnológicas no país, admitindo-se, conforme estabelece o Decreto no 5.773/06, em seu art. 44, cursos experimentais em oferta legal e regular, porém com outras denominações [...] (BRASIL, 2010, p. 9). 
Assim como qualquer nível da Educação Escolar, a Educação Profissional de Nível Tecnológico é orientada pelos princípios enunciados pelo Artigo $3^{\circ}$ da LDB. Há ainda princípios citados pelo Parecer CNE/CP n²9/2002 que tratam especificamente da educação profissional de nível tecnológico como "Promover a capacidade de continuar aprendendo e de acompanhar as mudanças nas condições do trabalho, bem como propiciar o prosseguimento de estudos em cursos de pós-graduação" e "Adotar a flexibilidade, a interdisciplinaridade, a contextualização e a atualização permanente dos cursos e seus currículos" (BRASIL, 2002, p. 35).

\section{CONSIDERAÇÕES FINAIS}

Reafirma-se a importância da formação integral dos professores, especialmente destes que iniciam sua profissionalização docente carentes de uma formação inicial voltada ao ensinar. Admite-se que os conhecimentos técnicos consolidados na prática extradocente influenciam e qualificam a sua prática, mas não são suficientes.

Se a literatura valoriza os diferentes pilares edificadores da identidade docente, admitindo diversos saberes igualmente importantes, resta destacar a importância de um programa de formação continuada baseado na construção do conhecimento, bem como pontua Piaget, na interação entre o sujeito e o objeto, ou entre o professor e o exercício da sua profissão.

Acredita-se, portanto, que se pautada no paradigma bancário, de depósito de teorias educacionais e filosóficas, mesmo a formação continuada não oportunizaria a transformação e a melhoria do ensino que tanto se clama. Crêse que os professores, detentores de saberes diversos, enriqueceriam ainda mais suas práticas por meio do diálogo, da reflexão e na troca com os pares.

Também cabe destacar a importância de definição e cumprimento de políticas públicas que asseguram a oferta e a permanência dos professores nesses programas, especialmente admitindo que o exercício de qualificação e reflexão sobre a prática faz parte do fazer docente.

Na análise dos documentos oficiais, é possível perceber que a legislação que ampara o Ensino Superior Tecnológico está preocupada com a construção de uma educação que contemple a visão crítica do mercado de trabalho e com a formação de alunos que buscam a aprendizagem constante, a fim de melhorar 
a sociedade. Resta questionar se a iniciativa de ofertar uma educação integral e crítica não é uma ação exclusivamente legislativa.

Por isso, precisa-se estar atento para a formação e atuação docente para que a Educação Superior Tecnológico esteja além dos parâmetros de formação de mão de obra para o mercado de trabalho.

A construção da identidade docente dos professores brasileiros do Ensino Superior Tecnológico, que não possuem formação específica voltada para a docência, ainda carece de efetivos programas. Estes precisam resultar numa construção identitária com a docência, a exemplo do que postula a legislação e a literatura em tela.

\section{REFERÊNCIAS}

BECKER, F. A epistemologia do professor: O cotidiano da escola. 14 ed. Petrópolis, RJ: Vozes, 2009.

BRASIL. Catálogo Nacional de Cursos Superiores de Tecnologia. Secretaria da Educação Profissional e Tecnológica. Ministério da Educação, Brasília, 2010.

BRASIL. Centenário da Rede Federal de Educação Profissional e Tecnológica. Ministério da Educação, Brasília, 2009. Disponível em: <http://portal.mec.gov.br/ setec/arquivos/ centenario/historico_educacao_profissional.pdf $>$. Acesso em: 18 jul. 2012.

BRASIL. Parecer CNE/CP: 29/2002, Diretrizes Curriculares Nacionais Gerais para a Educação Profissional de Nível Tecnológico. Relator: Conselheiro Francisco Aparecido Cordão. Aprovado em 03 dez. 2002. Diário Oficial da União, DF, 13 dez. 2002. Disponível em: < http://portal.mec.gov.br/cne/arquivos/pdf/cp29.pdf>. Acesso em: 15 out. 2011.

FRANCO, S. R. K. O construtivismo na educação. 4. ed. Porto Alegre: Mediação, 1995.

IMBERNÓN, F. Formação continuada de professores. Porto Alegre: Artmed, 2010. FREIRE, P. Pedagogia do Oprimido. 46. ed. Rio de Janeiro: Paz e Terra, 2005.

MIZUKAMI, M. G. N. et al. Escola e aprendizagem da docência: processos de investigação e formação. São Carlos: EdUFSCar, 2002.

SIMÕES, D. D. R.; CASTANHO, M. E. Ensino técnico: desde o período colonial à era neoliberal. Disponível em: <http://www.google.com.br/url?sa=t\&rct=j\& $q=\& e s r c=s \&$ source $=$ web \&cd $=1 \&$ ved $=0 C C Q Q F j A A \& u r l=h t t p \% 3 A \% 2 F \% 2 F w$ ww.histedbr.fae.unicamp.br\%2Facer_histedbr\%2Fseminario\%2Fseminario $8 \% 2$ F_files\%2FKrTbCuBK.doc\&ei=FJaeUPOtHoSQ9gT2yYCgBg\&usg=AFQjCNGgKT66 Y_PYTX-WWCS3OEWW74vvdw> . Acesso em: 16 out. 2012. 
TARDIF, M. Saberes docentes e formação profissional. Petrópolis: Vozes, 2012.

NOTA

1 As informações trazidas neste e nos próximos quatro parágrafos se referem à mesma fonte: Brasil, 2009. 